\title{
Acute splenic sequestration in a cohort of children with sickle cell anemia
}

\author{
Sequestro esplênico agudo em coorte de crianças com anemia falciforme \\ Paulo V. Rezende ${ }^{1}$, Marcos B. Viana', Mitiko Murao', Ana Cristina Leite Chaves ${ }^{3}$, \\ Ana Cristina F. Ribeiro ${ }^{4}$
}

\section{Resumo}

Objetivo: Analisar o sequestro esplênico agudo (SEA) em crianças com anemia falciforme, provindas da triagem neonatal de Minas Gerais e acompanhadas pelo Hemominas de Belo Horizonte (MG).

Métodos: Coorte retrospectiva de 255 crianças com hemoglobinopatia SS $/ \mathrm{S} \beta^{0}$, nascidas entre $01 / 01 / 2000$ e 31/12/ 2004 e acompanhadas até $31 / 12 / 2006$. Os dados foram extraídos dos prontuários médicos.

Resultados: Oitenta e nove pacientes apresentaram 173 eventos de SEA (10,2 primeiros eventos por 100 pacientes/ano), sendo que $75 \%$ dos primeiros episódios de SEA ocorreram até 2 anos de vida. A probabilidade estimada de ocorrência do primeiro episódio de SEA foi de $40 \%$. A recorrência atingiu $57,3 \%$. Após o primeiro episódio de SEA, a esplenectomia foi indicada em apenas $12,4 \%$ dos casos; após o segundo, em $60,4 \%$ dos casos. Após o terceiro episódio, $41,7 \%$ dos casos ainda permaneceram sob observação clínica. A mediana do tempo entre indicação e realização da esplenectomia foi de 2 meses. Nesse intervalo, 37,2\% das crianças tiveram novo episódio de SEA e uma delas faleceu. A letalidade no primeiro episódio foi de 1,1\% e de 7,8\% em episódios subsequentes. Entre as 255 crianças ocorreram 19 óbitos: $36,8 \%$ devido a infecções e $26,3 \%$ após SEA.

Conclusões: O SEA é um evento comum na anemia falciforme, principalmente nos 2 primeiros anos de vida, com recidiva em mais da metade dos casos. Predominou conduta conservadora na indicação da esplenectomia. Embora a letalidade tenha sido baixa, o SEA representou a segunda causa de óbito. Isso aponta para fragilidades estruturais do sistema de saúde de MG e para a necessidade de melhor capacitação profissional na abordagem do problema.

J Pediatr (Rio J). 2009;85(2):163-169: Anemia falciforme, sequestro esplênico agudo, crianças, esplenectomia, teste do pezinho, mortalidade.

\begin{abstract}
Objective: To analyze acute splenic sequestration (ASS) in children with sickle cell anemia diagnosed through a newborn screening program in the state of Minas Gerais, Brazil, and followed up at the hematology center in the city of Belo Horizonte, Minas Gerais, Brazil.
\end{abstract}

Methods: Retrospective cohort of 255 children with sickle cell anemia $\left(\mathrm{Hb} \mathrm{SS} / \mathrm{S} \beta^{\circ}\right)$ born between January 01, 2000, and December 31,2004 , and followed up until December 31, 2006. Data were abstracted from the patients' medical records.

Results: A total of 89 patients had 173 episodes of ASS (10.2 first episodes per 100 patient-years); $75 \%$ of the first episodes occurred before 2 years of age. The estimated probability of occurrence of the first episode of ASS during the study period was $40 \%$. Recurrence rate reached $57.3 \%$. After the first episode, splenectomy was indicated in only $12.4 \%$ of the cases; after the second, in $60.4 \%$ of the cases. After the third episode, $41.7 \%$ of the patients remained under clinical observation. The median time between indication for splenectomy and the actual surgical procedure was 2 months. During the intervening period, $37.2 \%$ of the children suffered a new episode of ASS and one child died. Case-fatality rate was $1.1 \%$ for the first episode and $7.8 \%$ for the subsequent episodes. Among a total of 255 children, 19 died: $36.8 \%$ due to infections and $26.3 \%$ after ASS.

Conclusions: ASS is relatively common in sickle cell anemia, mainly in the first 2 years of life; relapse occurs in more than half of the cases. Conservative management instead of immediate splenectomy was the method of choice. Although the case-fatality rate was low, ASS was the second most common cause of death. These results disclose some fragilities of the health system in the state of Minas Gerais and the need for better professional education to approach ASS crises.

J Pediatr (Rio J). 2009;85(2):163-169: Sickle cell anemia, acute splenic sequestration, children, splenectomy, newborn screening, mortality.

1. Mestre. Serviço de Hematologia, Hospital das Clínicas, Universidade Federal de Minas Gerais (UFMG), Belo Horizonte, MG. Fundação Hemominas, Belo Horizonte, MG.

2. Doutor. Professor titular, Departamento de Pediatria, Faculdade de Medicina, UFMG, Belo Horizonte, MG.

3. Acadêmica de Medicina, Faculdade de Medicina, UFMG, Belo Horizonte, MG.

4. Médica. Faculdade de Medicina, UFMG, Belo Horizonte, MG.

Apoio: Conselho Nacional de Desenvolvimento Científico e Tecnológico (CNPq): Marcos B. Viana é bolsista 1D do órgão de fomento à pesquisa.

Não foram declarados conflitos de interesse associados à publicação deste artigo.

Como citar este artigo: Rezende PV, Viana MB, Murao M, Chaves AC, Ribeiro AC. Acute splenic sequestration in a cohort of children with sickle cell anemia. J Pediatr (Rio J). 2009;85(2):163-169.

Artigo submetido em 15.12.08, aceito em 04.02.09.

doi:10.2223/JPED.1885 


\section{Introdução}

A doença falciforme é um problema de saúde pública em todo o mundo. No Brasil, o número estimado de indivíduos com traço falciforme é de 7.200 .000 , com prevalência na população geral entre 2 e $8 \%{ }^{1}$. Em Minas Gerais, a incidência do traço no Programa Estadual de Triagem Neonatal (PETNMG) é de $3,3 \%{ }^{2}$.

Sequestro esplênico agudo (SEA) refere-se a uma complicação comum nas crianças com anemia falciforme. Caracteriza-se pelo aprisionamento de hemácias no baço, com consequente aumento de tamanho do órgão e queda dos níveis de hemoglobina. Ele é considerado a segunda causa de morte na primeira década de vida, logo após os episódios infecciosos $^{3-7}$. Os eventos apresentam prevalência de 7,5 a $30 \%$, ocorrendo com maior frequência entre 3 meses e 5 anos de idade (76\% antes dos 2 anos) e em pacientes com hemoglobinopatia SS.

As crises de sequestração não têm etiologia definida. Acredita-se que ocorra desvio do fluxo sanguíneo através de shunts intraesplênicos, o que provoca aumento do órgão, com retenção de hemácias e ingurgitamento capilar ${ }^{4,8-11}$. Não há evidências de padrão sazonal que sugira causa infecciosa. Clinicamente, os episódios são considerados uma emergência médica: os pacientes podem apresentar sinais de choque hipovolêmico, que evolui para óbito em poucas horas. $\mathrm{O}$ tratamento eficaz consiste no diagnóstico precoce, suporte clínico e transfusão de concentrado de hemácias. Existem relatos que demonstram elevada taxa de recorrência e de mortalidade ${ }^{4,6-8,12-19}$.

O manejo subsequente das crises ainda é motivo de discussão. As opções são: observação clínica atenta, esquema de transfusões periódicas de concentrado de hemácias e esplenectomia. Os estudos clínicos sobre o SEA são retrospectivos, descritivos, não-controlados e levantam algumas questões sobre a real função esplênica após os episódios, além de vantagens e desvantagens de esplenectomia comparadas às transfusões crônicas $3,11,13,20,21$.

Não existem dados nacionais sobre o SEA publicados em revistas indexadas. Visando a preencher essa lacuna, o objetivo deste estudo foi estudar as características clínicas, epidemiológicas e de tratamento do SEA em crianças triadas pelo PETN-MG e acompanhadas no ambulatório da Fundação Centro de Hematologia e Hemoterapia de Belo Horizonte (Hemominas).

\section{Métodos}

O estudo foi uma coorte retrospectiva, descritiva, utilizando dados obtidos dos prontuários médicos arquivados no Hemominas e em banco de dados do PETN-MG. A população consistiu, inicialmente, de todas as 284 crianças com perfil eletroforético FS ao nascimento $\left(\mathrm{SS} / \mathrm{S} \beta^{\circ}\right)$, nascidas entre 1 de janeiro de 2000 e 31 de dezembro de 2004. Reviu-se a evolução clínico-laboratorial dos pacientes até 31 de dezembro de 2006, de modo que todas as crianças foram acompanhadas por, no mínimo, 2 anos.

Foram incluídos como casos os 89 pacientes que apresentaram um ou mais episódios de SEA, definidos como o registro do evento no prontuário médico pelo hematologista responsável pelo acompanhamento da criança. O registro de cada episódio de SEA é realizado com base em relatórios médicos de atendimento dos pacientes em serviços de urgência, relatando os eventos, suas características clínicas, condutas tomadas e evolução da criança. Constituíram o grupocontrole as 166 crianças sem registro de SEA, totalizando 255 pacientes analisados.

Foram excluídos da análise 29 pacientes pelos seguintes motivos: outros perfis eletroforéticos na confirmação com 6 meses de vida ( $2 \mathrm{~S}^{+}$talassemia e $1 \mathrm{SD}$ ); 11 crianças que não foram seguidas até os 2 anos de idade, por qualquer razão, exceto o óbito; e 15 pacientes encaminhados para outro estado ou outro hemocentro no estado de MG até os 2 anos de idade.

O formulário de cada criança incluía identificação, dados hematológicos basais (hemoglobina, leucometria, plaquetometria, contagem de reticulócitos e eletroforese de hemoglobina) e tamanho basal do baço à palpação no exame físico. Todos os valores hematológicos foram transcritos das anotações médicas, na ausência de processos infecciosos ou crise álgica, e, no mínimo, 3 meses após uso de hemocomponentes. A média aritmética de cada item foi considerada como valor basal para cada paciente. A dosagem de hemoglobina fetal basal foi obtida a partir das eletroforeses de hemoglobina registradas no prontuário médico de cada paciente. Optou-se por considerar a eletroforese realizada na idade mais avançada dentro do período de acompanhamento, desde que tivesse sido colhida após 12 meses de vida, quando a concentração fisiológica de hemoglobina fetal já se encontra relativamente estável.

Em relação ao SEA, foram avaliados, durante a crise, dados clínicos (tamanho do baço e sintomas associados) e hematológicos já citados, presença ou não de assistência médica, condutas tomadas durante os eventos, evolução clínica e seguimento dessas crianças. Nas eventuais recorrências, colheram-se os mesmos dados.

As informações relacionadas aos pacientes que evoluíram para o óbito foram obtidas dos prontuários médicos do Hemominas, de cópia das certidões de óbito fornecidas pelo PETN-MG e a partir de dados de entrevistas realizadas por Fernandes $^{22}$, descritas em sua dissertação de mestrado.

A taxa de mortalidade geral até os 2 anos de vida foi calculada dividindo-se o número de óbitos até os 2 anos de vida 
pela população exposta, uma vez que todos os pacientes tiveram a oportunidade de ser acompanhados, pelo menos, até essa idade.

A curva de probabilidade de ocorrência do primeiro episódio de SEA foi construída baseada no método de KaplanMeier. Foram "censuradas" as crianças que evoluíram para o óbito, caso este não tenha sido causado pelo primeiro episódio de SEA, ou as que não apresentaram episódio de SEA até a data de encerramento do estudo.

A associação da ocorrência ou não do SEA com o sexo, município de residência (capital ou interior), presença de esplenomegalia basal, nível de hemoglobina, porcentagem de hemoglobina fetal, contagens basais de leucócitos, plaquetas e reticulócitos, foi verificada utilizando-se o qui-quadrado ou teste de Fisher para variáveis nominais, e teste $t$ ou de Mann-Whitney para variáveis contínuas, com distribuição normal ou não-normal, respectivamente. Consideraram-se significativos os testes em que a probabilidade de erro alfa foi $\leq$ 0,05 .

O estudo foi aprovado pelo Comitê de Ética em Pesquisa da Hemominas em 07/08/2006, registro número 141.

\section{Resultados}

Foram analisadas 255 crianças, sendo $123(48,2 \%)$ do sexo masculino e $132(51,8 \%)$ do feminino. Foram identificados 173 eventos de SEA que ocorreram em 89 pacientes, com incidência de 10,2 primeiros eventos por 100 pacientes/ano. Apenas um episódio de SEA foi identificado em 38 pacientes, sendo que 51 pacientes tiveram dois ou mais SEA, com taxa de recorrência de $57,3 \%$.

A idade ao primeiro evento variou entre 2,3 meses e 6 anos e 3 meses (mediana de 16,6 meses); 75\% deles ocorreram até 23,5 meses de vida. A probabilidade acumulada de ocorrência do primeiro episódio de SEA para todo o período estudado foi $40 \%$ (Figura 1 ).

Apenas uma criança não teve assistência médica na vigência do SEA. Predominou o atendimento em hospitais terciários de Belo Horizonte e Hemominas $(57,8 \%)$ em detrimento de assistência médica no interior (26,6\%).

Os valores dos exames laboratoriais hematológicos basais e durante os 173 episódios de SEA encontram-se resumidos na Tabela 1.

Em 91 episódios havia registro de diagnósticos associados ao SEA, sendo as doenças infecciosas as mais comuns $(89,6 \%)$. Em 24 episódios não se registrou qualquer associação e, em 58, o prontuário médico era omisso.

A conduta frente ao episódio agudo foi acompanhamento clínico ou indicação de esplenectomia. Nenhuma criança foi incluída em programa de transfusão crônica de hemácias.

Foram indicadas 51 esplenectomias nas 89 crianças que tiveram SEA; 48 foram efetivamente realizadas. Em dois casos, a família não autorizou a realização do procedimento. Permaneceram em observação clínica e não apresentaram

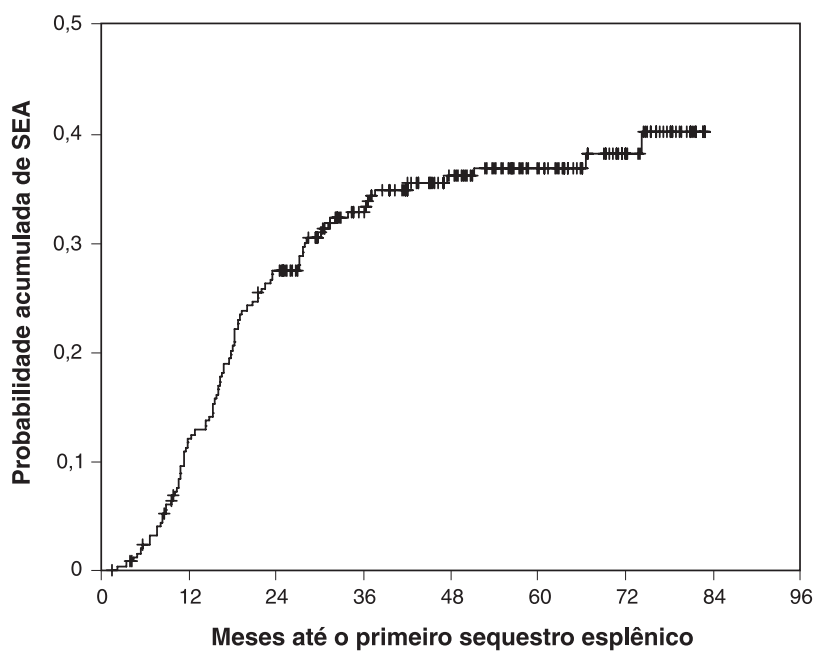

SEA = sequestro esplênico agudo.

Figura 1 - Curva de probabilidade de ocorrência do primeiro episódio de sequestro esplênico agudo, conforme tempo de exposição de cada criança (Método de KaplanMeier)

novos episódios de SEA. Uma outra criança, que teve a esplenectomia indicada após dois episódios de SEA, apresentou novo episódio e faleceu antes da realização do procedimento. A Tabela 2 mostra as indicações de esplenectomia, discriminadas por episódio de SEA.

A mediana do tempo de espera entre a indicação da esplenectomia e sua realização foi de aproximadamente 2 meses; $25 \%$ das crianças aguardaram tempo superior a 5 meses. No intervalo entre a indicação e a realização das cirurgias, 19 pacientes $(37,2 \%)$ tiveram novo episódio de SEA e uma delas evoluiu para o óbito, como já mencionado. Dessas 19 crianças, duas apresentaram dois novos episódios enquanto aguardavam o procedimento.

Na população total estudada ( $n=255$ ) ocorreram 19 óbitos, sendo sete associados a infecções, cinco devidos ao SEA, quatro de causa desconhecida, dois por "insuficiência respiratória" e um em estado de coma (possível acidente vascular cerebral). A idade ao óbito variou entre 45 dias e 5 anos e 6 meses (mediana de 10 meses). A taxa de mortalidade aos 2 anos de vida foi de $5,1 \%$ [intervalo de confiança de $95 \%$ (IC95\%) 2,4-7,8]. As probabilidades estimadas de sobrevida com 1,2 e 5 anos são de 96,1 (IC95\% 93,7-98,5), 94,9 (IC95\% 92,2-97,6) e 92,4\% (IC95\% 88,8-96,0), respectivamente. A letalidade pelo SEA no primeiro episódio foi de $1 / 89$ $(1,1 \%$, IC95\% 0-3,26) e a dos episódios subsequentes $4 / 51$ (7,8\%, IC95\% 0,5-15,2).

A Tabela 3 mostra a associação entre SEA e as variáveis pesquisadas.

\section{Discussão}

No presente estudo, a incidência de SEA foi de 10,2 primeiros episódios por 100 pacientes/ano, com recorrência de 
Tabela 1 - Exames hematológicos basais dos pacientes incluídos no estudo, realizados entre 1 e 2 anos de idade, na ausência de processos infecciosos ou crise álgica e 3 meses após uso de hemocomponentes (basal): exames hematológicos durante os 173 episódios de SEA

\begin{tabular}{lcc}
\hline Exame hematológico & Basal & SEA \\
\hline Hemoglobina $(\mathrm{g} / \mathrm{dL})$ & $8,0(7,4-9,1), \mathrm{n}=250$ & $4,6(3,8-7,5), \mathrm{n}=138$ \\
Leucometria $\left(\mathrm{x} 10^{9} / \mathrm{L}\right)$ & $14,4(11,0-18,9), \mathrm{n}=250$ & $17,5(14,4-25,3), \mathrm{n}=71$ \\
Reticulócitos $(\%)$ & $14,0(8,5-16,8), \mathrm{n}=247$ & $18,8(17,0-21,3), \mathrm{n}=24$ \\
Plaquetometria (x 10\%) & $357,7(289,5-432,7), \mathrm{n}=250$ & $110,5(80,0-143,5), \mathrm{n}=82$ \\
Hemoglobina fetal (\%) & $21,0(15,0-29,0), \mathrm{n}=230$ & - \\
\hline
\end{tabular}

SEA = sequestro esplênico agudo.

Tabela 2 - Indicações de esplenectomia em 89 crianças que apresentaram, no mínimo, um episódio de SEA

\begin{tabular}{|c|c|c|c|c|}
\hline $\begin{array}{l}\text { Indicação de } \\
\text { esplenectomia }\end{array}$ & Após $1^{\circ}$ episódio & Após $2^{\circ}$ episódio* & Após $3^{\circ}$ episódio & Após $4^{\circ}$ episódio \\
\hline Sim & $11(12,4 \%)$ & $29(60,4 \%)$ & $7(58,3 \%)$ & $4(100 \%)$ \\
\hline Não & $78(87,6 \%)$ & $19(39,6 \%)$ & $5(41,7 \%)$ & $0(0 \%)$ \\
\hline Total & 89 & 48 & 12 & 4 \\
\hline
\end{tabular}

$57,3 \%$. Incidências semelhantes (8,2 e 9,2 episódios por 100 pacientes/ano) foram encontradas por outros autores ${ }^{8,23} . \mathrm{Em}$ relação à recorrência de eventos, os resultados de outros autores são semelhantes ao encontrado, com taxas de 49, 50 e $71 \%{ }^{8,13,14}$.

Não houve associação estatisticamente significativa do gênero com o desenvolvimento de SEA, à semelhança do encontrado por outros autores $4,6,8,12,14,24$. Também a maior frequência de SEA em lactentes foi igualmente relatada por outros estudos $4,8-10,13-15,20,25$.

A curva de probabilidade de ocorrência do primeiro episódio de SEA (Figura 1) indica a estimativa de que 27,1, 33 e $37 \%$ das crianças já teriam sofrido o primeiro episódio de SEA quando atingida a idade de 2, 3 e 5 anos, respectivamente. A estimativa jamaicana ${ }^{8}$, utilizando metodologia semelhante, foi de 22,5, 26, 5 e 29,7\% aos 2, 3 e 5 anos, respectivamente. Na coorte americana ${ }^{12}$, as estimativas, nos mesmos pontos, foram de 8,10 e $12 \%$.

Em relação aos exames laboratoriais hematológicos basais e durante os episódios de SEA (Tabela 1), outros estudos mostram resultados bastante semelhantes ao encontrado na presente casuística ${ }^{4,6,25}$.

Em relação aos fatores clínicos associados, 52,6\% dos episódios de SEA apresentaram algum outro diagnóstico clínico associado, sendo $89,6 \%$ relacionado a doenças infecciosas. A revisão da literatura mostra que a etiologia do SEA não é conhecida. Alguns autores destacaram uma possível associação com processos infecciosos agudos, mas sem conseguirem estabelecer uma relação direta de causa-efeito $9,15,26$.

Os dados constantes da Tabela 2 demonstram uma clara convergência na indicação da esplenectomia após dois ou mais episódios de SEA. A maioria dos autores, entretanto, recomenda a realização de esplenectomia após o primeiro ${ }^{4,6,21}$ ou, no máximo, após o segundo episódio de $\mathrm{SEA}^{5,8,11,15}$, o que denota uma conduta conservadora por parte dos médicos assistentes na presente casuística, talvez influenciada pelas dificuldades socioeconômicas e de compreensão das famílias atendidas e pelos obstáculos do acesso a serviços capacitados para o procedimento cirúrgico. Os dados sobre o tempo entre a indicação da esplenectomia e a realização do procedimento são preocupantes. Os resultados expõem a lentidão do Sistema Único de Saúde e a existência de entraves burocráticos que geram uma demora injustificável no processo até a realização da cirurgia.

Os pacientes que tiveram palpação do baço abaixo do rebordo costal esquerdo durante algum momento da evolução clínica apresentaram risco aumentado de aproximadamente 2 vezes de ter um episódio de SEA em relação àqueles sem esplenomegalia. Resultado semelhante foi encontrado na Jordânia ${ }^{14}$. Não foi observada associação estatisticamente significativa entre desenvolvimento de SEA e valores de hemoglobina, plaquetometria ou contagem de reticulócitos (Tabela 3), dados que condizem com a literatura ${ }^{8,14}$. Entretanto, crianças que não tiveram SEA apresentaram níveis significativamente mais elevados de hemoglobina fetal do que 
Tabela 3 - Fatores associados ao desenvolvimento de SEA

\begin{tabular}{|c|c|c|c|}
\hline Variável & Crianças com SEA & Crianças sem SEA & $\mathbf{p}$ \\
\hline Sexo & & & $0,78 *$ \\
\hline Masculino & 44 & 79 & \\
\hline Feminino & 45 & 87 & \\
\hline Município de residência & & & $0,69 *$ \\
\hline Capital & 20 & 41 & \\
\hline Interior & 69 & 125 & \\
\hline Esplenomegalia basal & & & $0,01 *$ \\
\hline Sim & 51 & 67 & \\
\hline Não & 38 & 99 & \\
\hline $\begin{array}{l}\text { Hemoglobina basal }(\mathrm{g} / \mathrm{dL}) \text {, } \\
\text { mediana }(25-75 \%)\end{array}$ & $7,9(7,3-9,2)$ & $8,1(7,4-8,9)$ & $0,58^{+}$ \\
\hline $\begin{array}{l}\text { Plaquetometria basal }\left(\times 10^{9} / \mathrm{L}\right) \text {, } \\
\text { mediana }(25-75 \%)\end{array}$ & $359(285,5-451,5)$ & $360(294-430)$ & $0,96^{+}$ \\
\hline $\begin{array}{l}\text { Contagem de reticulócitos (\%), } \\
\text { mediana }(25-75 \%)\end{array}$ & $14(8,9-17)$ & $14,2(8,5-17,4)$ & $0,92^{+}$ \\
\hline $\begin{array}{l}\text { Leucometria basal }\left(\times 10^{9} / \mathrm{L}\right) \text {, } \\
\text { mediana }(25-75 \%)\end{array}$ & $12,9(9,6-17,6)$ & $15,4(12,4-19,4)$ & $0,001^{+}$ \\
\hline $\begin{array}{l}\text { Hemoglobina fetal (\%), mediana } \\
(25-75 \%)\end{array}$ & $19(15-28)$ & $23(16-30)$ & $0,03^{+}$ \\
\hline
\end{tabular}

SEA = sequestro esplênico agudo.

* Teste de qui-quadrado.

+ Teste de Mann-Whitney.

aqueles que tiveram SEA. Tal associação já foi descrita por vários estudos ao longo do tempo e tem sido justificada pelo fato de que hemácias com maior quantidade de hemoglobina fetal possuem níveis mais baixos de hemoglobina S, apresentando menor chance de falcização e, consequentemente, menor probabilidade de manifestações clínicas $8,10,11,27,28$. Observou-se, ainda, associação estatisticamente significativa entre leucometria basal mais baixa e desenvolvimento de SEA. Não foi encontrado resultado semelhante nos diversos artigos pesquisados na literatura médica. As associações observadas, embora estatisticamente significativas, foram fracas e não permitem predizer com razoável segurança qual criança seria mais sujeita a SEA, o que não Ihes confere relevância clínica.

No presente estudo, a letalidade geral do SEA foi de 5 óbitos em 173 episódios de SEA (2,9\%), bem menor do que o relatado na coorte jamaicana $(9,8 \%)^{8}$. Contudo, o número de óbitos por causa indeterminada $(4 / 19=21,1 \%)$ foi bastante elevado, o que poderia significar subestimação da letalidade do SEA por falta de reconhecimento desse como causador do óbito, conforme constatado em estudo feito com crianças do PETN-MG 22 .

A avaliação das causas dos 19 óbitos indicou os processos infecciosos como o principal causador de óbitos $(36,8 \%)$, seguido pelo SEA (26,3\%). Os resultados encontrados são similares aos dados publicados por alguns autores $^{12,15,16,18,19,25}$. Entre os dados nacionais, o estudo de Fernandes $^{22}$ revelou que o SEA foi responsável, quando se utilizou o documento de óbito para determinar-lhe a causa, por $13(16,6 \%)$ dos 78 óbitos, sendo a segunda causa conhecida mais frequente, seguindo as complicações infecciosas. Estudo também realizado em MG demonstrou baixa adesão ao uso de antibiótico profilático ${ }^{29}$, o que, parcialmente, explica esses dados.

A mortalidade infantil para as crianças com anemia falciforme do presente estudo, independentemente de terem ou não sofrido episódio de SEA, foi de 3,9\%, ou seja, 39/1.000 pacientes. De acordo com dados do Sistema de Informações sobre Mortalidade do Ministério da Saúde, a taxa de mortalidade infantil em Minas Gerais em 2002 foi de 18/1.000. Descontada a taxa de mortalidade neonatal precoce (óbitos entre 0 e 6 dias de vida, período usualmente anterior à realização da triagem neonatal), a taxa de mortalidade em MG foi de $8 / 1.000$, valor 4,8 vezes menor do que a verificada no presente estudo. Isso indica que, mesmo com o diagnóstico precoce propiciado pela triagem neonatal em MG, ainda falecem no primeiro ano de vida mais crianças com anemia falciforme do que o esperado. Não há como comparar a situação atual com a anterior à triagem pela inexistência de dados.

A principal limitação do estudo refere-se ao diagnóstico preciso do episódio de SEA, classicamente definido como 
aumento súbito do volume esplênico, associado à queda de pelo menos $2 \mathrm{~g} / \mathrm{dL}$ na concentração de hemoglobina e reticulocitose. Num estudo de base populacional retrospectivo, é impraticável atingir tal nível de precisão, pois o diagnóstico de evento agudo, como o SEA, é realizado em vários hospitais, policlínicas e unidades básicas de saúde, não sendo possível, em vários casos, a recuperação de todos os dados laboratoriais. O protocolo adotado fiou-se, estritamente, no registro do evento no prontuário do Hemocentro, o que pode tanto importar em uma possível sub ou superestimação da incidência do SEA.

O presente estudo traz à tona uma reflexão sobre a situação das crianças com anemia falciforme no contexto do sistema de saúde pública brasileira. O SEA é uma das intercorrências clínicas mais comuns na evolução das crianças com anemia falciforme, com características marcantes e diagnóstico relativamente simples, mas que muitas vezes não é reconhecido devido ao despreparo da equipe, insuficiente educação dos pais para lidar com os problemas, dificuldades socioeconômicas, e falta de transporte seguro e rápido das crianças afetadas e de recursos para realização imediata de transfusão de hemocomponentes e de exames hematológicos básicos. Não se pode negar que alguns passos importantes para tentar melhorar a situação já foram dados em vários estados e, em particular, em MG. A triagem neonatal para doença falciforme, a realização de treinamentos periódicos para várias equipes de saúde, a criação e divulgação de protocolos específicos para o manejo dos eventos agudos da doença, além de acompanhamento multidisciplinar em instituições especializadas e, de forma destacada, a educação familiar $^{8,25,30}$ constituem a esperança de que as dificuldades possam ser superadas em curto e médio prazos.

Fica evidente que não se trata de um problema de resolução simples, uma vez que a situação não é simples. Porém, o presente estudo serve como um alerta de que ainda há um longo caminho pela frente. O programa de atenção integral à pessoa com doença falciforme é um objetivo a ser alcançado por todos os envolvidos, incluindo gestores, profissionais de saúde e familiares. As questões relacionadas à doença devem ser reconhecidas como prioritárias para o adequado atendimento global, não da doença falciforme, mas da criança com doença falciforme.

\section{Referências}

1. Cançado RD, Jesus JA. A doença falciforme no Brasil. Rev Bras Hematol Hemoter. 2007;29:204-6.

2. Paixão MC, Cunha Ferraz MH, Januário JN, Viana MB, Lima JM. Reliability of isoelectrofocusing for the detection of $\mathrm{HbS}, \mathrm{HbC}$, and $\mathrm{HbD}$ in a pioneering population-based program of newborn screening in Brazil. Hemoglobin. 2001;25:297-303.
3. Owusu-Ofori S, Hirst C. Splenectomy versus conservative management for acute sequestration crises in people with sickle cell disease. Cochrane Database of Systematic Reviews. 2002, Issue 4: CD003425. http://mrw. interscience.wiley.com/ cochrane/clsysrev/articles/CD003425/frame.html . Acesso: 26/ 01/2009.

4. Topley JM, Rogers DW, Stevens MC, Serjeant GR. Acute splenic sequestration and hypersplenism in the first five years in homozygous sickle cell disease. Arch Dis Child. 1981;56:765-9.

5. Al-Salem AH. Indications and complications of splenectomy for children with sickle cell disease. J Pediatr Surg. 2006; 41:1909-15.

6. Powell RW, Levine GL, Yang YM, Mankad VN. Acute splenic sequestration crisis in sickle cell disease: early detection and treatment. J Pediatr Surg. 1992;27:215-9.

7. National Heart, Lung, and Blood Institute. Splenic Sequestration. In: National Heart, Lung, and Blood Institute; National Institutes of Health. The management of sickle cell disease. Bethesda, MD: NIH; 2002. p. 119-22.

8. Emond AM, Collis R, Darvill D, Higgs DR, Maude GH, Serjeant GR. Acute splenic sequestration in homozygous sickle cell disease: natural history and management. J Pediatr. 1985; 107:201-6.

9. Jenkins ME, Scott RB, Baird RL. Studies in sickle cell anemia. XVI. Sudden death during sickle cell anemia crises in young children. J Pediatr. 1960;56:30-8.

10. Bainbridge R, Higgs DR, Maude GH, Serjeant GR. Clinical presentation of homozygous sickle cell disease. J Pediatr. 1985; 106:881-5.

11. Serjeant GR. The spleen. In: Serjeant GR. Sickle cell disease 2nd ed. Oxford: Oxford Medical Publication; 1992. p. 135-52.

12. Gill FM, Sleeper LA, Weiner SJ, Brown AK, Bellevue R, Grover R, et al. Clinical events in the first decade in a cohort of infants with sickle cell disease. Cooperative Study of Sickle Cell Disease. Blood. 1995;86:776-83.

13. Al-Hawsawi ZM, Ismail GA. Acute splenic sequestration crisis in children with sickle cell disease. Saudi Med J. 2001;22:1076-9.

14. Al-Rimawi HS, Abdul-Qader M, Jallad MF, Amarin ZO. Acute splenic sequestration in female children with sickle cell disease in the North of Jordan. J Trop Pediatr. 2006;52:416-20.

15. Seeler RA, Shwiaki MZ. Acute splenic sequestration crises (ASSC) in young children with sickle cell anemia. Clinical observations in 20 episodes in 14 children. Clin Pediatr (Phila). 1972;11:701-4.

16. Rogers DW, Clarke JM, Cupidore L, Ramlal AM, Sparke BR, Serjeant GR. Early deaths in Jamaican children with sickle cell disease. $\mathrm{Br}$ Med J. 1978;1:1515-6.

17. Thomas AN, Pattison C, Serjeant GR. Causes of death in sickle-cell disease in Jamaica. Br Med J (Clin Res Ed). 1982; 285:633-5.

18. Gray A, Anionwu EN, Davies SC, Brozovic M. Patterns of mortality in sickle cell disease in the United Kingdom. J Clin Pathol. 1991;44:459-63.

19. Manci EA, Culberson DE, Yang YM, Gardner TM, Powell R, Haynes J Jr, et al. Causes of death in sickle cell disease: an autopsy study. $\mathrm{Br}$ J Haematol. 2003; 123:359-65.

20. Kinney TR, Ware RE, Schultz WH, Filston HC. Long-term management of splenic sequestration in children with sickle cell disease. J Pediatr. 1990;117:194-9. 
21. Pearson HA, Gallagher D, Chilcote R, Sullivan E, Wilimas J, Espeland $\mathrm{M}$, et al. Developmental pattern of splenic dysfunction in sickle cell disorders. Pediatrics. 1985;76:392-7.

22. Fernandes AP. Caracterização e circunstâncias da ocorrência de óbitos em crianças com doença falciforme triadas pelo Programa Estadual de Triagem Neonatal de Minas Gerais, no período de março de 1998 a fevereiro de 2005 [dissertação]. Belo Horizonte, MG: Universidade Federal de Minas Gerais; 2007.

23. King L, Fraser R, Forbes M, Grindley M, Ali S, Reid M. Newborn sickle cell disease screening: the Jamaican experience (1995-2006). J Med Screen. 2007;14:117-22.

24. Neonato $M G$, Guilloud-Bataille $M$, Beauvais $P$, Bégué $P$, Belloy $M$, Benkerrou M, et al. Acute clinical events in 299 homozygous sickle cell patients living in France. French Study Group on Sickle Cell Disease. Eur J Haematol. 2000;65:155-64.

25. Vichinsky E, Hurst D, Earles A, Kleman K, Lubin B. Newborn screening for sickle cell disease: effect on mortality. Pediatrics. 1988;81:749-55

26. Sprague CC, Paterson JC. Role of the spleen and effect of splenectomy in sickle cell disease. Blood. 1958;13:569-81.

27. Stevens MC, Hayes RJ, Vaidya S, Serjeant GR. Fetal hemoglobin and clinical severity of homozygous sickle cell disease in early childhood. J Pediatr. 1981;98:37-41.
28. Bailey K, Morris JS, Thomas P, Serjeant GR. Fetal haemoglobin and early manifestations of homozygous sickle cell disease. Arch Dis Child. 1992;67:517-20.

29. Bitarães EL, de Oliveira BM, Viana MB. Compliance with antibiotic prophylaxis in children with sickle cell anemia: a prospective study. J Pediatr (Rio J). 2008;84:316-22.

30. Wright JG, Hambleton IR, Thomas PW, Duncan ND, Venugopal S, Serjeant GR. Postsplenectomy course in homozygous sickle cell disease. J Pediatr. 1999;134:304-9.

Correspondência:

Marcos Borato Viana

Faculdade de Medicina - Departamento de Pediatria

Universidade Federal de Minas Gerais

Avenida Alfredo Balena, 190/267

CEP 30130-100 - Belo Horizonte, MG

Tel.: (31) 3409.9772

Fax: (31) 3409.9770

E-mail: vianamb@gmail.com 